\section{Intrasilicone oil injection of bevacizumab at the end of retinal reattachment surgery for severe proliferative vitreoretinopathy}

K Ghasemi Falavarjani, M Hashemi, M Modarres and A Hadavand Khani
Eye Research Center, Rassoul Akram Hospital, Iran University of Medical Sciences, Tehran, Iran

Correspondence: K Ghasemi Falavarjani, Eye Research Center, Rassoul Akram Hospital, Sattarkhan-Niaiesh St Tehran, Iran

Tel: + 9891 21725850;

Fax: + 982166509162

E-mail: drghasemi@

yahoo.com

Received: 3 April 2013 Accepted in revised form: 30 December 2013 Published online: 21 February 2014

\begin{abstract}
Purpose To evaluate the role of bevacizumab injected into the silicone oil at the end of retinal reattachment surgery for rhegmatogenous retinal detachment (RRD) associated with severe proliferative vitreoretinopathy (PVR) for prevention of postoperative PVR and compare the results with those without intrasilicone injection. Methods In this prospective comparative interventional study, eyes with RRD with grade C PVR were included. Standard 20 gauge pars plana vitrectomy, and retinal reattachment was performed. In case group, $1.25 \mathrm{mg}$ bevacizumab was injected into the silicone oil at the end of surgery. The rate of retinal redetachment associated with PVR was assessed.

Results In all 38 eyes of 38 patients (19 cases and 19 controls) with a mean age of $46.6 \pm 18.3$ years were studied. The two groups were matched for age, sex, preoperative visual acuity, presence of anterior and posterior PVR, extent of PVR, and history of previous retinal detachment surgery. Retinal redetachment with PVR occurred in nine $(47.3 \%)$ and seven $(36.8 \%)$ eyes in case and control groups, respectively $(P=0.5)$. Extensive subretinal fibrous proliferations in addition to preretinal membranes occurred more in the case group (55.5 vs 14.3\%). At final visit, visual acuity was similar between the two groups $(1.6 \pm 0.8$ and $1.6 \pm 0.6$, respectively, $P=0.9$ ).

Conclusion Intrasilicone injection of bevacizumab at the end of vitrectomy for RRD with severe PVR does not eliminate the risk of postoperative PVR.
\end{abstract}

Eye (2014) 28, 576-580; doi:10.1038/eye.2014.21; published online 21 February 2014

Keywords: bevacizumab; rhegmatogenous retinal detachment; proliferative vitreoretinopathy

\section{Introduction}

Rhegmatogenous retinal detachment (RRD) is a sight-threatening condition with an incidence of 10-15 per 100000 persons. ${ }^{1,2}$ Although a growing number of RRDs is successfully repaired with a single procedure, proliferative vitreoretinopathy (PVR) is still the major cause of failure of the surgery. ${ }^{3-5}$ PVR is believed to be a wound healing process with inflammation, migration, and proliferation of resident ocular cells including retinal pigment epithelial cells and invading immune cells leading to formation of adherent membranes, which are able to contract and cause recurrent retinal detachment. ${ }^{5}$

Previous studies have shown altered expression of growth factors and cytokines in vitreous, subretinal fluid and membranes in patients with PVR. ${ }^{6-9}$ The association of vascular endothelial growth factor (VEGF) with the pathogenesis of PVR, has been reported by several authors. VEGF levels were found to be higher in subretinal fluid and vitreous fluid samples of PVR compared with uncomplicated RRD. ${ }^{9-13}$ Considering the role of VEGF in the pathogenesis of PVR, it is rational to consider anti-VEGF medications as a potential modality for prevention of PVR.

Bevacizumab (Avastin, Genentech, Inc., South San Francisco, CA, USA) is a monoclonal 
antibody that binds to all VEGF isoforms. ${ }^{14}$ It has been approved for the treatment of colorectal cancer by Food and Drug Administration, but not for intraocular injection. Nevertheless, its 'off label' intraocular injection is being successfully used for the treatment of different ocular diseases associated with neovascularization. ${ }^{15-21}$

The aim of this study was to evaluate the results of intrasilicone bevacizumab injection at the end of vitrectomy in a series of patients with RRD associated with PVR and to compare the results with those of a control group.

\section{Patients and methods}

In this prospective comparative interventional study, from January to August 2012, all patients with RRD and PVR (grade C) ${ }^{22}$ were included. The case group consisted of patients who were operated between January and April. Intrasilicone injection of bevacizumab was performed at the end of reattachment surgery in this group. The patients who underwent surgery after this time served as controls.

Patients with other intraocular diseases that may affect the course of the retinal detachment repair including uveitis, proliferative diabetic retinopathy (PDR), retinal vascular disorders, congenital vitreoretinopathies, and those with traumatic RRD were excluded. Institutional review board/ethics committee of the Rassoul Akram Hospital Eye Research Center approved the study. Informed consents were obtained from the patients. In the case group, the limited therapeutic options for preventing the recurrence of PVR as well as off-label nature of bevacizumab injection were explained.

All surgeries were performed by one surgeon (KGF). Standard three-port 20 gauge pars plana vitrectomy was performed. After removing the core vitreous, posterior vitreous detachment was induced and meticulous membrane peeling was performed. In eyes without a circumferential scleral buckle, a circumferential episcleral band was inserted to support the vitreous base and endolaser photocoagulation of the breaks and $360^{\circ}$ of the peripheral retina was performed. In cases with significant retinal shortening or unreleasable contractures, retinotomy or retinectomy was performed. Silicone oil was used for endotamponade in all eyes. In the case group, before closure of inflow sclerotomy, 0.05 cc $(1.25 \mathrm{mg})$ of commercially available Avastin solution (Genentech Inc. (made for F. Hoffmann-La Roche Ltd, Basel, Switzerland)) was injected into the silicone oil. At the conclusion of surgery, subtenon injection of triamcinolone acetonide was performed. On the first postoperative day, topical antibiotic eye drop was administered four times daily for 2 weeks and topical betametason eye drop was prescribed every $2 \mathrm{~h}$ for 1 week and then four times daily for the next 2 weeks. All patients received oral prednisolone $50 \mathrm{mg}$ daily for 10 days. To ensure that the redetachment is not due to the incorrect surgical technique, patients with retinal redetachment during first three postoperative weeks were excluded. The surgical procedure and postoperative medications were the same for both groups except for intrasilicone injection of bevacizumab in the case group.

The patients were visited 1 day, 1 week, 1 month, 3 month, and at the last follow-up after surgery. In patients without recurrent retinal detachment after surgery, the follow-up was continued for at least 6 months. Primary outcome measure was the rate of recurrence of retinal detachment due to PVR and the secondary outcome measure was visual acuity.

Statistical analysis was performed with SPSS software (IBM Inc., Chicago, IL, USA) and $P<0.05$ was considered significant. Paired $t$-test, independent $t$-test, Fisher's exact test and $\chi^{2}$-test were used for analysis.

\section{Results}

In all 38 eyes of 38 patients (19 eyes in each group) with a mean age of $46.6 \pm 18.3$ years were studied. Baseline characteristics including age, sex, baseline visual acuity, presence of anterior and posterior PVR, and extent of PVR were statistically similar between the two groups (Table 1). No patient developed redetachment during first month. Mean follow-up time was $7.3 \pm 2.1$ months.

In both groups, visual acuity improved significantly at final visit ( $P<0.001$ for both groups). At final visit, visual acuity was statistically similar between the case and control group $(1.6 \pm 0.8$ and $1.6 \pm 0.6$, respectively, $P=0.9)$. Visual acuity improved in 12 eyes $(63.1 \%)$ in case group and 13 eyes $(68.4 \%)$ in controls.

Retinal redetachment occurred in nine $(47.3 \%)$ and seven $(36.8 \%)$ eyes in case and control groups, respectively $(P=0.5)$, all due to PVR. Macula was detached in six eyes $(31.5 \%)$ in case group and five eyes $(26.3 \%)$ in control group. In the case group, the postoperative redetachment was associated with extensive subretinal fibrous proliferations in addition to preretinal membranes in five eyes $(55.5 \%)$, however, subretinal fibrous proliferations were only seen in one eye in the control group (14.3\%). The mean interval between vitrectomy and retinal redetachment was $6.5 \pm 1.7$ weeks in case group and $6.5 \pm 1.0$ weeks in control group $(P=1)$.

\section{Discussion}

PVR is the most common cause of failure in retinal detachment surgery. ${ }^{3,4}$ It is comprised of a cascade of 
Table 1 Baseline characteristics and major outcomes of patients with retinal detachment and PVR who underwent retinal reattachment surgery

\begin{tabular}{lccc}
\hline & Case group & Control group & P-value \\
\hline Age (year) & $43.7 \pm 19.01$ & $49.4 \pm 17.6$ & $0.4^{\mathrm{a}}$ \\
Sex (male/female) & $14 / 5$ & $14 / 5$ & 7 \\
Number of eyes with history of surgery for retinal detachment & 12 & 14 & $0.2^{\mathrm{b}}$ \\
Preoperative number of eyes with anterior PVR & 17 & 14 & $0.4^{\mathrm{c}}$ \\
Preoperative number of eyes with posterior PVR & 10 & $4.0 \pm 2.9$ & $0.3^{\mathrm{b}}$ \\
Preoperative extent of PVR (clock hour) & $3.1 \pm 2.1$ & $2.5 \pm 0.6$ & $0.3^{\mathrm{a}}$ \\
Presenting visual acuity (LogMAR) & $2.3 \pm 0.7$ & $1.6 \pm 0.6$ & $0.3^{\mathrm{a}}$ \\
Final visual acuity (LogMAR) & $1.6 \pm 0.8$ & $0.9^{\mathrm{a}}$ \\
Number of eyes with retinal detachment after reattachment surgery & 9 & $0.5^{\mathrm{a}}$
\end{tabular}

Abbreviation: PVR, proliferative vitreoretinopathy.

${ }^{\mathrm{a}} \mathrm{t}$-test.

${ }^{\mathrm{b}} \chi^{2}$-test.

${ }^{\mathrm{c}}$ Fisher's exact test.

events including inflammation, migration, and proliferation of a variety of cells. Several attempts have been undertaken to target various points along the PVR cascade, however, limited success has been achieved. The use of antiproliferative agents, corticosteroids, nonsteroidal anti-inflammatory drugs, and low molecular weight heparin has not been proven to be efficacious in the prevention or treatment of PVR, and the need for an effective pharmacological treatment is sensible. ${ }^{23-25}$

Although the exact role of VEGF in the pathogenesis of the PVR has not been established, several recent studies show a strong association between VEGF and PVR. Ogata et $a l^{9}$ reported significantly higher vitreous level of VEGF in PVR eyes compared with eyes with simple retinal detachment or macular hole. Citiric et al ${ }^{11}$ evaluated the VEGF concentrations in PDR in comparison with PVR and found that vitreous VEGF concentrations were increased in both PDR and grade $\mathrm{C}$ PVR. Ricker et al ${ }^{12}$ measured VEGF level in subretinal fluid of patients with and without PVR and reported a two to threefold increase in the level of VEGF in the PVR group. Considering these results, VEGF could be a potential target for the elimination of PVR and the use of anti-VEGF agents may help to prevent the development of PVR. Furthermore, previous studies suggested an antiinflammatory role for anti-VEGF agents and this may be another reason for using anti-VEGFs for prevention of PVR. ${ }^{26}$ Mehdizadeh $e t$ al ${ }^{27}$ evaluated the effect of intravitreal bevacizumab on an experimental rabbit model of penetrating posterior ocular injury. They reported significant reduction in the incidence and dimension of fibrous proliferation in the bevacizumab group. To the best of our knowledge, there is no study reporting the effect of anti-VEGF agents in eyes with RRD and PVR.

Our study focused on patients with grade $C$ preoperative PVR, which are known to be at increased risk for subsequent PVR and surgical failure. ${ }^{28}$ Previous studies reported an anatomical success rate of $35-75 \%$ after one surgery in patients with RRD associated with severe PVR. ${ }^{28}$ In the hallmark Silicone Study, recurrent retinal detachment developed in $55 \%$ of eyes without prior vitreous surgery and $65 \%$ of eyes with prior vitreous surgery that were randomized to silicone oil. ${ }^{29}$ Our anatomic success rate of 52.7 and $63.2 \%$, in the case and control group, suggests that intrasilicone injection of bevacizumab is not effective for eliminating the postoperative PVR and may not reduce its rate, as well. It has been shown that several cytokines in addition to VEGF are upregulated after the onset of RRD in patients in whom postoperative PVR develops after primary RRD repair. ${ }^{13,30}$ Targeting one cytokine alone may not be enough for prevention of PVR. Most of the patients with retinal redetachment in our bevacizumab study group had subretinal fibrous proliferations leading to the need for subretinal surgery. Similar finding has been reported in patients with PDR and neovascular age-related macular degeneration after treatment with intravitreal bevacizumab. ${ }^{31,32}$ Van Geest et al ${ }^{33}$ showed that the connective tissue growth factor level correlates positively, and VEGF level correlates negatively with the degree of vitreoretinal fibrosis, and intravitreal bevacizumab injection causes an increase in the clinical and intraoperative amount of fibrosis in patients with PDR. This mechanism may be responsible for development of subretinal fibrosis in a significant number of our patients.

We injected $1.25 \mathrm{mg}$ bevacizumab into the silicone oil. The diffusion of bevacizumab out of the silicone oil may result in accumulation in the meniscus of the fluid underneath silicone oil. $\mathrm{Xu}$ et $a l^{34}$ reported normal halflife of bevacizumab after intrasilicone injection of $1.25 \mathrm{mg}$ bevacizumab in vitectomized silicone filled eyes in rabbits, although the peak concentration was delayed in various ocular tissues. This shows that the effective 
concentration of the bevacizumab remains in the eye and does not washout during first few weeks after intrasilicone injection.

The non-randomized nature of this study and small sample size are the major limitations of our study. In this study, we only included patients with advanced PVR. The response in eyes with RRD without PVR or with mild forms of PVR may be different. Our study groups were matched for basic characteristics including age, sex, visual acuity, previous retinal surgery, and extent of PVR, and the surgical procedure was the same for both groups. Although difficult, further matching according to the other known risk factors for PVR improves the validity of the results.

In conclusion, although our study is underpowered to detect a significant difference between the two groups, the results show that intrasilicone injection of bevacizumab at the end of vitrectomy for RRD with advanced PVR does not prevent postoperative PVR formation and may be associated with formation of severe subretinal membranes. This is a pilot study, and further randomized studies with large sample size and different grades of PVR are needed to elucidate the role of anti-VEGF agents in surgery for RRD associated with PVR.

\section{Summary}

\section{What was known before}

- Proliferative vitreoretinopathy is associated with increased vitreous and subretinal level of vascular endothelial growth factor.

\section{What this study adds}

- Intrasilicone injection of bevacizumab at the end of vitreoretinal surgery for proliferative vitreoretinopathy does not prevent development of subsequent proliferative vitreoretinopathy and may be associated with subretinal membrane proliferation.

\section{Conflict of interest}

The authors declare no conflict of interest.

\section{References}

1 Haimann MH, Burton TC, Brown CK. Epidemiology of retinal detachment. Arch Ophthalmol 1982; 100: 289-292.

2 Wilkes SR, Beard CM, Kurland LT, Robertson DM, $\mathrm{O}^{\prime}$ Fallon WM. The incidence of retinal detachment in Rochester, Minnesota, 1970-1978. Am J Ophthalmol 1982; 94: 670-673.

3 D'Amico DJ. Clinical practice. Primary retinal detachment. N Engl J Med 2008; 359: 2346-2354.

4 Pastor JC. Proliferative vitreoretinopathy: an overview. Surv Ophthalmol 1998; 43: 3-18.
5 Pastor JC, de la Rúa ER, Martín F. Proliferative vitreoretinopathy: risk factors and pathobiology. Prog Retin Eye Res 2002; 21: 127-144.

6 Fredj-Reygrobellet D, Baudouin C, Nè gre F, Caruelle JP, Gastaud P, Lapalus P. Acidic FGF and other growth factors in preretinal membranes from patients with diabetic retinopathy and proliferative vitreoretinopathy. Ophthalmic Res 1991; 23: 154-161.

7 Chen YS, Hackett SF, Schoenfeld CL, Vinores MA, Vinores SA, Campochiaro PA. Localisation of vascular endothelial growth factor and its receptors to cells of vascular and avascular epiretinal membranes. Br J Ophthalmol 1997; 81: 919-926.

8 Spraul CW, Kaven C, Lang GK, Lang GE. Effect of growth factors on bovine retinal pigment epithelial cell migration and proliferation. Ophthalmic Res 2004; 36: 166-171.

9 Ogata N, Nishikawa M, Nishimura T, Mitsuma Y, Matsumura M. Inverse levels of pigment epitheliumderived factor and vascular endothelial growth factor in the vitreous of eyes with rhegmatogenous retinal detachment and proliferative vitreoretinopathy. Am J Ophthalmol 2002; 133: $851-852$

10 Su CY, Chen MT, Wu WS, Wu WC. Concentration of vascular endothelial growth factor in the subretinal fluid of retinal detachment. J Ocul Pharmacol Ther 2000; 16: 463-469.

11 Citirik M, Kabatas EU, Batman C, Akin KO, Kabatas N. Vitreous vascular endothelial growth factor concentrations in proliferative diabetic retinopathy versus proliferative vitreoretinopathy. Ophthalmic Res 2012; 47(1): 7-12.

12 Ricker LJAG, Dieudonne SC, Kessels AGH, Rennel ES, Berendschot TT, Hendrikse F et al. Antiangiogenic isoforms of vascular endothelial growth factor predominate in subretinal fluid of patients with rhegmatogenous retinal detachment and proliferative vitreoretinoapthy. Retina 2011; 32(1): 54-59.

13 Rasier R, Gormus U, Artunay O. Vitreous levels of VEGF, IL-8, and TNF- $\alpha$ in retinal detachment. Current Eye Res 2010; 35: 505-509.

14 Ferrara N, Hillan KJ, Gerber HP, Novotny W. Discovery and development of bevacizumab, an anti-VEGF antibody for treating cancer. Nat Rev Drug Discov 2004; 3(5): 391-400.

15 Grisanti S, Ziemssen F. Bevacizumab: off-label use in ophthalmology. Indian J Ophthalmol 2007; 55(6): 417-420.

16 Avery RL, Pieramici DJ, Rabena MD, Castellarin AA, Nasir MA, Giust MJ. Intravitreal bevacizumab (Avastin) for neovascular age-related macular degeneration. Ophthalmology 2006; 113(3): 363-372.

17 Modarres M, Naseripour M, Falavarjani KG, Nikeghbali A, Hashemi M, Parvaresh MM. Intravitreal injection of $2.5 \mathrm{mg}$ versus $1.25 \mathrm{mg}$ bevacizumab (Avastin) for treatment of CNV associated with AMD. Retina 2009; 29(3): 319-324.

18 Oshima Y, Sakaguchi H, Gomi F, Tano Y. Regression of iris neovascularization after intravitreal injection of bevacizumab in patients with proliferative diabetic retinopathy. Am J Ophthalmol 2006; 142(1): 155-158.

19 Falavarjani KG, Modarres M. Perioperative use of bevacizumab in vitrectomy for proliferative diabetic retinopathy: a literature review. Iranian J Ophthalmol 2010; 22(4): 5-12.

20 Falavarjani KG, Modarres M, Nazari H. Therapeutic effect of Bevacizumab injected into the silicone oil in eyes with neovascular glaucoma after vitrectomy for advanced diabetic retinopathy. Eye 2010; 24: 717-719.

21 Nazari H, Parvaresh MM, Modarres M, Falavarjani KG. Intravitreal bevacizumab in combination with laser therapy 
for the treatment of severe retinopathy of prematurity (ROP) associated with vitreous or retinal hemorrhage. Graefes Arch Clin Exp Ophthalmol 2010; 248: 1713-1718.

22 Machemer R, Aaberg TM, Freeman HM, Irvine AR, Lean JS, Michels RM. An updated classification of retinal detachment with proliferative vitreoretinopathy. Am J Ophthalmol 1991; 112: 159-165.

23 Charteris DG, Sethi CS, Lewis GP, Fisher SK. Proliferative vitreoretinopathy-developments in adjunctive treatment and retinal pathology. Eye 2002; 16: 369-374.

24 Wickham L, Bunce C, Wong D, McGurn D, Charteris DG. Randomized controlled trial of combined 5-fluorouracil and low-molecular-weight heparin in the management of unselected rhegmatogenous retinal detachments undergoing primary vitrectomy. Ophthalmology 2007; 114: 698-704.

25 Ahmadieh H, Feghhi M, Tabatabaei H, Shoeibi N, Ramezani A, Mohebbi MR. Triamcinolone acetonide in silicone-filled eyes as adjunctive treatment for proliferative vitreoretinopathy: a randomized clinical trial. Ophthalmology 2008; 115: 1938-1943.

26 Kiss C, Michels S, Prager F, Weigert G, Geitzenauer W, Schmidt-Erfurth U. Evaluation of anterior chamber inflammatory activity in eyes treated with intravitreal bevacizumab. Retina 2006; 26: 877-881.

27 Mehdizadeh M, Fattahi F, Eghtedari M, Nowroozzadeh $\mathrm{MH}$, Toosi $\mathrm{F}$. The role of intravitreal bevacizumab in experimental posterior penetrating eye injury. Retina 2011; 31(1): 154-160.
28 Asaria RHY, Gregor ZJ. Simple retinal detachments: identifying the at-risk case. Eye 2002; 16: 404-410.

29 The Silicone Study Group. Vitrectomy with silicone oil or perfluoropropane gas in eyes with severe proliferative vitreoretinopathy: results of a randomized clinical trial. Arch Ophthalmol 1992; 110: 780-792.

30 Ricker LJAG, Kijlstra A, Kessels AGH, de Jager W, Liem AT, Hendrikse F, La Heij EC. Interleukin and growth factor levels in subretinal fluid in rhegmatogenous retinal detachment: a case-control study. PLoS One 2011; 6(4): e19141.

31 Hwang JC, Del Priore LV, Freund KB, Chang S, Iranmanesh R. Development of subretinal fibrosis after anti-VEGF treatment in neovascular age-related macular degeneration. Ophthalmic Surg Lasers Imaging 2011; 42(1): 6-11.

32 Batman C, Ozdamar Y. The relation between bevacizumab injection and the formation of subretinal fibrosis in diabetic patients with panretinal photocoagulation. Ophthalmic Surg Lasers Imaging 2010; 41(2): 190-195.

33 Van Geest RJ, Lesnik-Oberstein SY, Tan HS, Mura M, Goldschmeding R, Van Noorden CJ. A shift in the balance of vascular endothelial growth factor and connective tissue growth factor by bevacizumab causes the angiofibrotic switch in proliferative diabetic retinopathy. $\mathrm{Br} J$ Ophthalmol 2012; 96(4): 587-590.

34 Xu Y, You Y, Du W, Zhao C, Li J, Mao J et al. Ocular pharmacokinetics of bevacizumab in vitrectomized eyes with silicone oil tamponade. Invest Ophthalmol Vis Sci 2012; 53: 5221-5226. 